\title{
Influential Effects of Product Quality on Trust, Brand Passion and Perceived Value
}

\author{
Apicha Boonpattarakan
}

\begin{abstract}
The objectives of this study were to investigate the effects of product quality as a second order construct on trust, brand passion, and perceived value as well as the effect of trust and perceived value on brand passion. The focus of this study was on the automobile industry. The dimensions of product quality were derived from in-depth interviews with car dealers and consumers. The second order dimensions of product quality adopted in this study were performance, features, durability, serviceability, and aesthetics. We performed confirmatory factor analysis by using LISREL to examine the measurement model consisting of convergent validity and discriminant validity. Both convergent validity and discriminant validity were found to be satisfactory. We then tested the theoretical model. The results indicated that product quality had the strongest effect on trust, followed by perceived value and brand passion. Trust also had a strong effect on brand passion while perceived value had a marginal effect on brand passion. All the first order dimensions of product quality construct were highly significant. The goodness of fit indices indicated a good fit of the model.
\end{abstract}

Keywords-Product Quality, Trust, Brand Passion, and Perceived Value

\section{INTRODUCTION}

A $\mathrm{S}$ a manufacturer, we all want to build a successful company and achieve a sustainable growth. In order to do that, we must use strategies to turn our customers into passionate customers, i.e., to have an extreme interest and love for our brand, which in this study will be referred to as brand passion. We also need to make consumers trust our product or brand and make them believe that our product or brand has high value, i.e., good quality product or brand with reasonable price, which will be referred to in this study as perceived value. If our customers had all these in their minds, they would help us by recommending others to buy our brand. This can be referred to as a word of mouth communication effect. In order to create trust, brand passion, and perceived value, manufacturers must first offer good product quality. They must emphasize their manufacturing process to produce quality products. However, different types of products may be evaluated differently in terms of the quality aspects of the products. In this study, we focused on the automobile industry and aimed at investigating the effects of product quality with key dimensions on trust, brand passion, and perceived value.

Apicha Boonpattarakan, International Research Promotion Institute Foundation, Thailand

\section{LITERATURE REVIEW}

\section{A. Product Quality}

The concept of quality is considered to be a fundamental concept emphasizing good products and services. With high quality work, firms will be able to function in the right direction and, hence, creating a competitive advantage for the firms (Kiran, 2017). High standards and high quality work are deemed to be the goal of the company. Without high standards and high quality work, it is difficult for firms to compete successfully in the market. Product quality is therefore a key element leading to the competitive success of the firm. The most general definition of a quality product perceived by everyone is the one that meets the expectations of customers (Hashmi, 2017). In this study, we follow the concept of product quality suggested by Garvin $(1987,1988)$, which consists of eight dimensions. These dimensions include performance, features, reliability, conformance, durability, serviceability, aesthetics, and perceived quality. According to Garvin (1987, 1988), performance refers to the primary operating function of a product. Features refer to the additional aspects that enhance the appeal of a product. Reliability is the failure of a product within a specific time. Conformance is referred to as meeting a specified standard or product specification. Durability refers to the life of a product. It has to meet the specified duration of using a product. Serviceability refers to the speed and ease of repair as well as the competence of servicepersons. Aesthetics is basically a person's preference or liking of the product. Perceived quality, the last dimension, refers to persons' feelings towards the product based on their perception of corporate image, brand image, and advertising. Our focus in this study is on the three major brands of cars in the automobile industry in Thailand. As a result, we interviewed six car dealers, two for each brand, and asked about the important level of those eight dimensions. We also interviewed thirty target respondents about the important level of those eight dimensions. The results indicated that performance, features, durability, serviceability, and aesthetics were the most important dimensions when they made their purchase decisions. Hence, in this study, our product quality construct will consist of these five dimensions and the construct is considered a second order factor. 


\section{B. Trust}

In the past two decades, trust has been studied extensively in the context of business relationships with commercial implications. The research on trust has been carried out in psychology, sociology, marketing, and organization behavior (Lewicki and Bunker, 1995; McLeary and Cruise, 2015; Mogan and Hunt, 1994). The concept of trust is therefore considered to be very important to the success of an on-going relationship. This on-going relationship may be between organizations and organizations or between people/persons and organizations. When we, as an organization, deal with other organizations, trust will play a major role in the organization who initiates a contact. We will refer to this type of dealing as business to business relationships. On the other hand, research studies have also been carried out to study business to customer relationships. Trust in this sense can be applied to companies that sell products or services (Yin et al., 2016). Sometimes, we may trust and rely more on one company than other companies. We may also trust and be more confident about a particular brand than other brands. We may trust and prefer a particular restaurant that we like. Many other corporations also face the same situation in the eye of consumers. Trust is therefore a central point to the success of the company. It is embedded in almost every type of businesses. In this study, trust is defined as consumers' beliefs and expectations that the merchants are reliable and will perform their obligations honestly.

\section{Brand Passion}

Passion is basically referred to as a strong liking or an extreme love or interest for a person or thing. It is a strong desire for something. It is about the intensity of feeling. It is similar to the concept of attitude but a strong and positive attitude toward something (Bauer et al., 2007). In the context of marketing, brand passion may be referred to as an extreme positive feeling or attitude toward a particular brand (Bauer et al., 2007). Brand passion appears to contain a very strong feeling of consumers toward a brand. If a consumer is passionate toward a particular brand, he or she will be likely to purchase and acquire that brand and become brand advocates. In addition, consumers will be likely to inform others concerning positive things about that brand. They are willing to talk about the brand in a very positive way and may try to convince others to pursue the same brand. In this sense, consumers have developed a very close relationship with the brand which may be called consumer-brand relationship (Albert et al., 2013). According to Albert et al. (2008), brand passion may consist of two parts. One has to do with the existence of the brand in the mind of consumers and the other has to do with the very high admiration of the brand. In this study, we define brand passion as a consumer's strong feeling, attachment, and obsession of a brand.

\section{D.Perceived Value}

Perceived value is deemed to be a key construct in marketing. To better understand customers' perceived value, we need to understand the value proposition. A value proposition is a comparison of the benefits customers receive and the price of the product customers have to pay. Perceived value can be referred to as the evaluation of perceived gains and costs. Perceived gains are considered to be the total benefits customers expect from purchasing a particular product while perceived costs are considered to be the total costs customers expect to incur in assessing, purchasing, and using the product (Kotler and Keller, 2016). Perceived value is fundamentally the net benefit received by the customer as a function of quality and price (Fredericks and Salter II 1995). Zeithaml (1988) proposes that elements of perceived value may include intrinsic attributes which are the physical aspects of the product (e.g., appearance of a car, interior design), extrinsic attributes which are the product-related factors not relevant to the physical aspects of the product (e.g., brand name), perceived quality, other abstractions (e.g., being proud of possessing a car), and sacrifices which may include both monetary (e.g., the price of a car) and nonmonetary prices (e.g., time for searching and acquiring). In this study, perceived value is defined as an overall assessment of the quality of a product and its price (Mencarelli and Lombart, 2017).

\section{E. Conceptual Framework}

In this study, product quality construct was considered to be the second order factor and its dimensions of performance, features, durability, serviceability, and aesthetics were considered to be the first order factors. On the other hand, brand passion, trust, and perceived value constructs were considered to be first order factors. We proposed that product quality will have positive effects on trust, brand passion, and perceived value. In addition, we also propose that trust and perceived value will have positive effects on brand passion. The conceptual framework was presented in Figure 1.

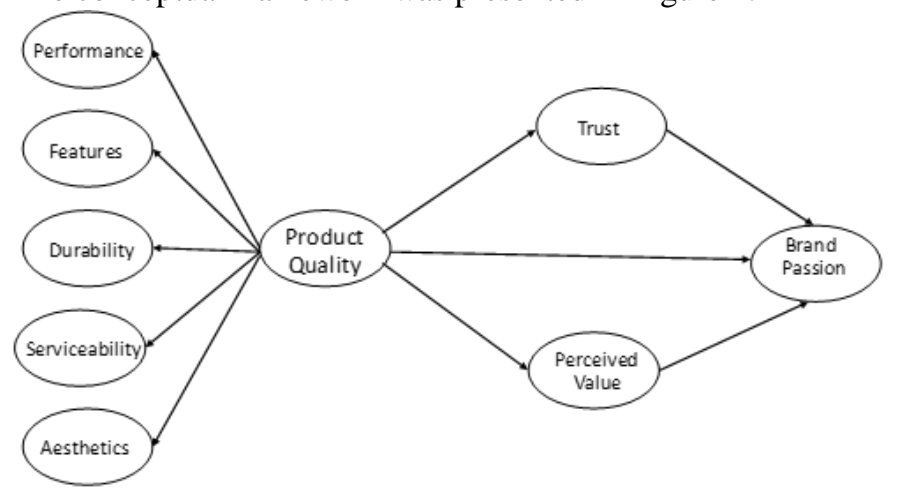

Fig. 1: The Conceptual Framework of the Study

\section{METHODOLOGY}

The population of interest was full-time employees working for companies in the Bangkok Metropolitan area in Thailand. We selected three major brands of cars whose prices were affordable. The prices were also comparable across all three brands. We selected respondents who had purchased a new car and owned a car for one to three years (warranty period). 
Based on Krejcie and Morgan (1970), our sample size was 384. Our measures were based on Likert scales and were adapted from existing measures as well as the definitions of the variables generally accepted in the literature. In order to perform reliability analysis, multiple items were used for each variable. A questionnaire was then developed. We then preliminarily tested the questionnaire by asking five qualified scholars to perform the IOC (Index of Item-Objective Congruence) for us. Those unclear questions were modified. A pretest was carried out using 50 respondents so that reliability analysis could be examined. Cronbach's alphas were computed. All the Cronbach's alphas were above 0.7 (Nunnally, 1978). The data collection method was face-toface interviews. We then collected 128 completed questionnaires from those respondents who owned the same brand. The total number of responses was 384 .

\section{ANALYSIS AND RESULTS}

Our sample consisted of $60.8 \%$ male and $39.2 \%$ female. The average age of respondents was 28.56 with standard deviation of 4.95. The majority of respondents had a bachelor's degree (72\%) and had income in the range of Baht 20,000 - 25,000 Baht (65.8\%). We then performed confirmatory factor analysis to examine convergent and discriminant validity by using the LISREL program. We tested the measurement model (i.e., the base model in our discriminant validity analysis) by treating product quality, trust, brand passion, and perceived value as four latent constructs and allowed them to covary. All the lambdas ( $\lambda$ 's) of the first order factors were above 0.6 ranging from 0.603 to 0.936 and gammas ( $\gamma$ 's) of the second order factors for product quality were highly significant with p-value less than 0.001 . The composite reliabilities of the first order factors ranged from 0.688 to 0.829 (above 0.6). All the AVEs were above 0.5 ranging from 0.517 to 0.711 . As a result, our model appeared to achieve convergence in measurement (Bagozzi and Yi, 1988). Following Phillips (1981), we tested discriminant validity among the four latent constructs by comparing the base model with the test model. In the test model, we constrained each of the intercorrelations $(\phi)$ to be 1.0 and then examined the differences in $\chi^{2}$ to see if they were significant. The results showed that the difference in $\chi^{2}$ with one degree of freedom between product quality and trust was 82.608 , between product quality and brand passion was 72.246 , between product quality and perceived value was 113.743, between trust and brand passion was 86.934, and between perceived value and brand passion was 131.686. All the differences in $\chi^{2}$ were highly significant $(p<0.001)$, suggesting the presence of discriminant validity among four latent constructs. We then tested our theoretical model (i.e., structural equation model) by using the LISREL program. The results were presented in Figure 2

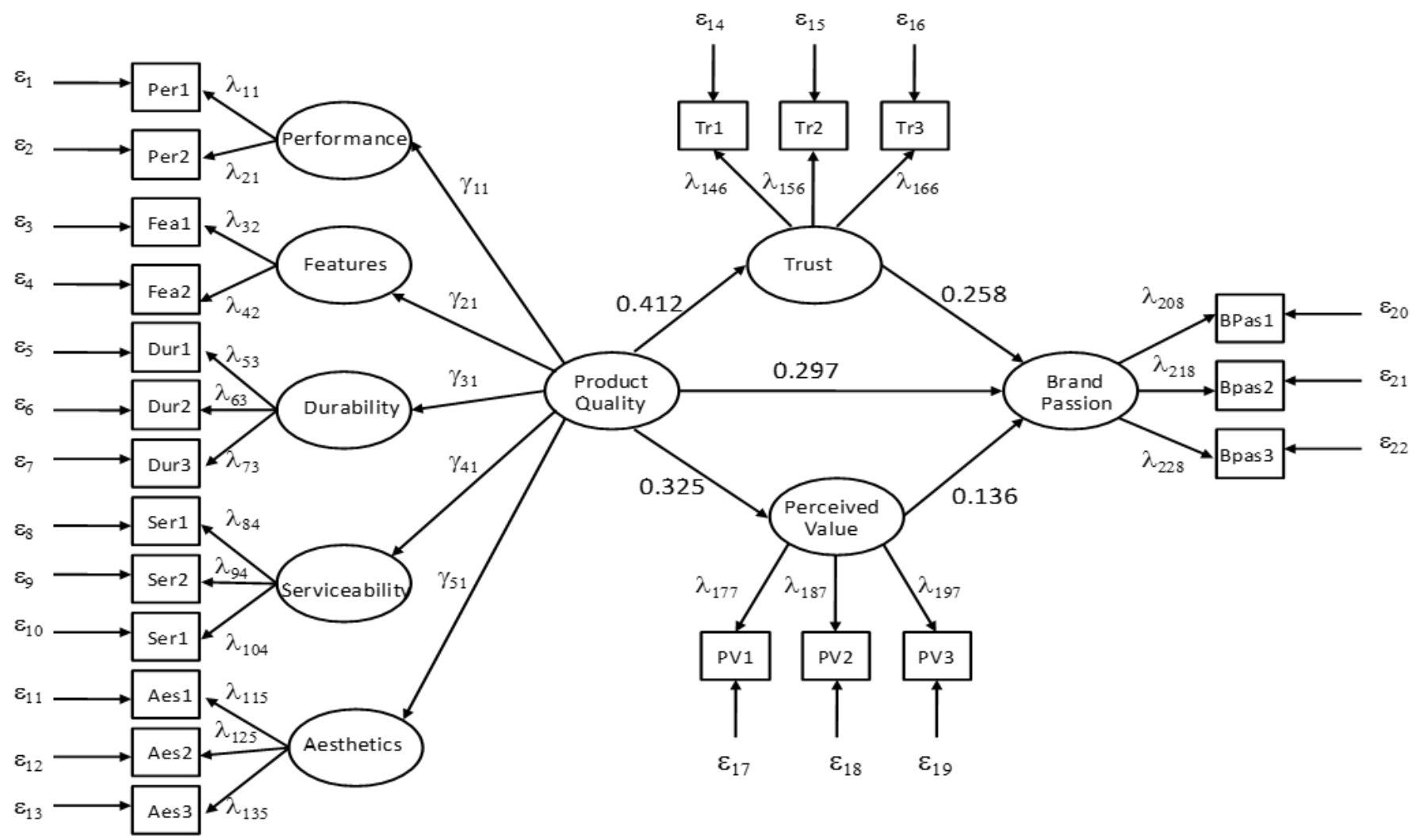

Fig. 2: Results of the Structural Equation Model 
The results from the structural equation model indicated that the coefficients (Gammas) of product quality - Trust, product quality - brand passion, and product quality - perceived value paths were highly significant $(\mathrm{p}<0.001)$. Product quality had positive effects on trust, brand passion, and perceived value. It appeared that the effect of product quality on trust was the strongest, followed by the effect of product quality on perceived value, and the effect of product quality on brand passion. The coefficient (Beta) of trust - brand passion path was also highly significant $(\mathrm{p}<0.001)$ while the coefficient (Beta) of perceived value - brand passion path was marginally significant ( $p<0.10)$. In this case, the effect of trust on brand passion was more important than the effect of perceived value on brand passion. We examined the fit indices. It appeared that chi-square $\left(\chi^{2}\right)$ was 425.718 with 199 degree of freedom. NFI, NNFI, CFI, and IFI were all above 0.9 while the goodness of fit index was 0.820 . The fit indices suggested a good fit of the model even though the goodness of fit index was 0.820 . This value was still acceptable. We also examined the values of gammas of the first order factors of the product quality construct. All of them were highly significant $(\mathrm{p}<$ 0.001). The results suggested that performance, features, durability, serviceability, and aesthetics were important in determining product quality.

\section{DISCUSSION}

Our structural equation model indicated that product quality had very significant effects on trust, brand passion, and perceived value. Product quality has the strongest effect on trust, followed by perceived value and brand passion. This suggests that customers will trust the brand, perceive the brand to be valuable, and have a strong love of the brand if that brand contains good product quality. In the automobile industry, product quality will be determined by its performance, features, aesthetics, durability, and serviceability. It appeared that the direct effect of trust on brand passion was more significant than the direct effect of perceived value on brand passion. Not only product quality had a direct effect on brand passion but it also had an indirect effect on brand passion through trust and perceived value. In order to generate brand passion, an extreme love of the brand, automobile companies need to focus on providing good quality product by emphasizing those five key dimensions. This will help create trust and perceived value which, in turn, will have an effect on brand passion. Creating consumers' brand passion is the ultimate goal of the company since it will help add value, image, reputation, and positive word-of-mouth communication. The contribution of this research is the test of the effect of product quality as a second order construct on trust, brand passion, and perceived value and the investigation of their interrelated effects. The study also adds another insight to the literature on brand passion.

\section{CONCLUSION}

This study was aimed at investigating the effects of product quality as a second order construct on trust brand passion, and perceived value as well as the effect of trust and perceived value on brand passion. The focus of this study was on the automobile industry. The dimensions of product quality were derived from the results of in-depth interviews and were composed of performance, features, durability, serviceability, and aesthetics. We performed confirmatory factor analysis by using LISREL to examine convergent validity and discriminant validity. The results of the measurement model indicated that both convergent validity and discriminant validity were achieved. We then tested the model by using the LISREL program. The results indicated a good fit of the model and showed that product quality had very strong effects on trust, brand passion, and perceived value. Trust also had a strong effect on brand passion while perceived value had a marginal effect on brand passion. All the first order dimensions of product quality construct were highly significant. It appeared that performance, features, durability, serviceability, and aesthetics were key elements in determining product quality in the automobile industry.

\section{REFERENCES}

[1] D. R. Kiran, Total Quality Management: Key Concepts and Case Studies. Cambridge, MA: Elsevier, 2017. https://doi.org/10.1016/B978-0-12-811035-5.00001-5

[2] K. Hashmi. (May 2017). Introduction and implementation of total quality management (TQM). Available: https://www.isixsigma.com/methodology/total-quality-managementtqm/introduction-and-implementation-total-quality-management-tqm/

[3] D. A. Garvin, "Competing on the eight dimensions of quality," Harvard Business Review, vol. 65, pp. 101-109, November-December 1987.

[4] D. A. Garvin, D. A., Managing Quality: The Strategic and Competitive Edge, New York, NY: The Free press, 1988.

[5] R. J. Lewicki and and B. B. Bunker, Trust in Relationships: A Model of Development and Decline, San Francisco, CA: Jossey-Bass, 1995.

[6] C. N. McLeary and P. A. Cruise, "A context-specific model of organizational trust: An examination of cognitive and socio-affective trust determinants in unique cultural settings," Cross Cultural Management, Vol. 22, pp. 297-320, 2015. https://doi.org/10.1108/CCM-11-2013-0180

[7] R. M. Morgan and S. D. Hunt, "The commitment-trust theory of relationship marketing," Journal of Marketing, vol. 58, pp. 20-38, July 1994. https://doi.org/10.2307/1252308

[8] S. Yin, M. Chen, Y. Chen, Y. Xu, Z. Zou, and Y. Wang, "Consumer trust in organic milk of different brands: The role of Chinese organic label," British Food Journal, vol. 118, pp. 1769-1782, 2016. https://doi.org/10.1108/BFJ-11-2015-0449

[9] H. H Bauer, D. Heinrich, and I. Marin, "How to create high emotional consumer-brand relationships? The causalities of brand passion," in Proc. 2007 the Australian and New Zealand Marketing Academy Conference, pp. 2189-98.

[10] N. Albert, D. Merunka, and P. Valette-Florence, "Brand passion: Antecedents and consequences," Journal of Business Research, vol. 66, pp. 904-909, 2013.

https://doi.org/10.1016/j.jbusres.2011.12.009

[11] N. Albert, D. Merunka, and P. Valette-Florence, "The love feeling toward a brand: Concept and measurement," Advances in Consumer Research, vol. 36, pp. 300-307, 2008.

[12] P. Kotler and K. L. Keller, Marketing Management, $15^{\text {th }}$ ed., Essex, England: Pearson Education Limited, 2016. 
[13] J. O. Fredericks and J. M. Salter II, "Beyond Customer Satisfaction," Management Review, vol. 84, pp. 29-32, May, 1995.

[14] V. A. Zeithaml, "Consumer perceptions of price, quality, and value: A means-end model and synthesis of evidence," Journal of Marketing, vol. 52, pp. 2-22, July 1988. https://doi.org/10.2307/1251446

[15] R. Mencarelli and C. Lombart, "Influences of the perceived value on actual repurchasing behavior: Empirical exploration in a retailing context," Journal of Retailing and Consumer Services, vol. 38, pp. 1221, 2017. https://doi.org/10.1016/j.jretconser.2017.04.008

[16] R. V. Krejcie and D. W. Morgan, D. W., "Determining sample size for research activities." Educational and Psychological Measurement, vol. 30, pp. 607-610, 1970 https://doi.org/10.1177/001316447003000308

[17] J. C. Nunnally, Psychometric Theory, $2^{\text {nd }}$ ed., New York, NY: McGrawHill, 1978.

[18] R. P. Bagozzi and Y. Yi, "On the evaluation of structural equation models." Journal of the Academy of Marketing Science, vol. 16, pp. 7494, January 1988. https://doi.org/10.1007/BF02723327

[19] L. W. Phillips, "Assessing measurement error in key informant reports: A methodological note on organizational analysis in marketing," Journal of Marketing Research, vol. 18, pp. 395-415, November 1981. https://doi.org/10.2307/3151333 